\title{
Developing sustainable bioenergy systems with local bio-resources: cases in Asia
}

\author{
Chun Sheng Goh ${ }^{1,2} \cdot$ Osamu Saito ${ }^{3} \cdot$ Yoshiki Yamagata $^{4}$
}

Received: 26 June 2020 / Accepted: 30 July 2020 / Published online: 10 August 2020

(c) Springer Japan KK, part of Springer Nature 2020

\begin{abstract}
The concept of sustainability science is paramount to establish a development thinking with deep and thorough considerations of hybridized on-ground realities shaped by the interplay of energy, land, economic, and climatic elements. This special feature intends to engage sustainability science in understanding the role of bioenergy in sustainable development, particularly for cases in East Asia. Especially, it encourages potential works that carefully consider perspectives of different stakeholders, including communicating with both experts and non-experts and integrating knowledge from different disciplines like forestry, social studies, or energy system sciences. It aims to create the context for motivating the society in tackling the sustainability issues related to energy, forest, and society.
\end{abstract}

Keywords Bioenergy $\cdot$ Bio-resources $\cdot$ Asia $\cdot$ Sustainability science $\cdot$ Forestry $\cdot$ Rural revitalization

\section{Introduction}

The recent adoption of the sustainable development goals (SDGs) framework marks a big departure from sectorialbased approaches, to a broader and overarching vision for improving people's lives, prosperity, and wellbeing. The framework established through the auspices of the United Nations (UN) aims to collectively reset the conventional economic-oriented development thinking with a broader set of social, environmental, and economic targets. The 17 SDGs are perceived as 'indivisible whole' with various types of interactions between them (Scharlemann et al. 2020). This implies that strategies must be carefully designed to optimize

Handled by Alexandros Gasparatos, University of Tokyo, Japan.

Chun Sheng Goh

chunshenggoh@fas.harvard.edu

1 Harvard University Asia Center, Cambridge, USA

2 Jeffrey Sachs Center on Sustainable Development, Sunway University, Subang Jaya, Malaysia

3 Institute for Global Environmental Strategies (IGES), Hayama, Japan

4 National Institute for Environmental Studies, Tsukuba, Japan synergies and trade-offs between the SDGs (Renaud et al. 2020).

Among the different energy pathways, bioenergy has an important role in linking several goals. It covers combinations of policy interventions not only across energy (SDG 7), and land use (agriculture and forestry) (SDG 15), but also rural development (SDG 8) and climate change (SDG 13). Transforming land-use and energy systems would require a more holistic development thinking beyond just 'land' or 'energy' but covering multiple aspects of a place or territory. The use of local bio-resources for energy purposes is not only perceived as an option to ease the stress of energy security in low population density areas due to high fuel cost and limited accessibility but also an opportunity to create new jobs and income for rural populations. Creating a domestic and regional production system for bioenergy as a means of replacing and/or complementing fossil fuels can potentially contribute to a self-sufficient circular economic ecosystem. Globally, several successes have been observed in countries such as Brazil (sugarcane ethanol) and Sweden (woody biomass for heat and power) with soundly designed financial support schemes (Silveira and Johnson 2016).

The concept of sustainability science is paramount to establish a development thinking with deep and thorough considerations of hybridized on-ground realities shaped by the interplay of energy, land, economic, and climatic 
elements. In the past, the journal has published several studies of bioenergy development across the world. Globally, Yamagata et al. (2018) demonstrate that large-scale bioenergy systems based on energy crops must be implemented with care even with productivity-boosting strategies like irrigation, considering the competition not only between food and fuel production, but also other limiting factors like water availability. Zooming into Sub-Saharan Africa, Hayashi et al. (2020) also showed that the role of this type of bioenergy systems in climate change mitigation may be lower than expected.

However, Wiek et al. (2015) reported that bioenergy can contribute to energy and livelihood security in rural Africa, where energy access and quality of life are low, through transdisciplinary collaboration oriented towards feasible solution options beyond sectorial constraints. Brewer et al. (2018) also demonstrated the key role of bioenergy in energy sovereignty of indigenous communities in Alaska where both fuel demand and cost are much higher than other parts of the country. Cleaner bioenergy for cooking may play an important role for sustainability transition in underdeveloped areas such as rural India and Kenya, but there are considerable technical, social, and economic constraints (Rehman et al. 2012; Karanja et al. 2020).

Importantly, bioenergy can be a critical part of forestry social-ecological systems. Maintaining healthy forests through the sustainable use of forestry products for various purposes is crucial in climate change mitigation. Based on the case of France, Sansilvestri et al. (2020) emphasized on the need to understand the priorities and capacities of forestry stakeholders, especially in terms of capital distribution and technical approaches. Matsumoto et al. (2019) also reported the potential synergies of forestry and climate change interventions in Indonesia, which has yet to be accounted effectively for in policymaking.

These studies demonstrated that the deployment of bioenergy systems is strongly affected or limited by multiple factors when viewed in a wider canvas, with local complexity especially urban-rural settings. To better understand the potential role of bioenergy, it is necessary to place it in a regional or national context of sustainable transformation. So far, there are few studies like these in Asia, especially the eastern part of the continent. In both developed and emerging regions in Asia, bioenergy has often been regarded as a potential option for energy security and rural development. Japan is a forerunner with a total of 16 GWe biomass power generation capacity approved by the end of 2017 (METI 2017). The current development relies heavily on biomass import, implying that the country will drastically attract a huge amount of bio-resources in the region if most of the approved capacity would be realized. South Korea shows a similar trend of development, while countries in Southeast Asia like Vietnam, Malaysia, and Indonesia tend to push for export rather than domestic use (Kang et al. 2015; Johari et al. 2015; Simangunsong et al. 2017). However, such import-oriented development has raised concerns about the sustainability of the entire bioenergy system in these countries (Junginger et al. 2019a).

In this context, the Asian countries may need to also explore opportunities from utilizing local bio-resources to cover domestic energy demand. Furthermore, healthy landscape management in conjunction with bio-production can contribute to multiple aspects of sustainability. In terms of environmental benefits, carbon removal and disaster prevention capability can be further enhanced with proper forest and landscape management while improving productivity (Matsumoto et al. 2019). Also, biomass can be strategically used to replace fossil fuels for both local heating and power generation based on local conditions (Karanja et al. 2020). Socio-economically, enhancing local bio-production for material and energy uses may become a key to revitalizing rural areas through various innovative business models (Wiek et al. 2015).

This special feature intends to engage sustainability science approaches in understanding the role of bioenergy for sustainable development, particularly in the East Asia content. Especially, it encourages potential works that carefully consider perspectives of different stakeholders, including communicating with both experts and non-experts and integrating knowledge from different disciplines like forestry, social studies, or energy system sciences. It aims to create the context for motivating the society in tackling the sustainability issues related to energy, forest, and society.

\section{An overview of the special feature}

First, Junginger et al. (2019b) reported the ongoing bioenergy development in East and Southeast Asia in recent years. The information was discussed and compiled through an international workshop organized in Tokyo in September 2018, and attended by government officials, industrial representatives, and researchers. The article illustrates the role of Japan (and to a lesser extent South Korea) in driving regional biomass trade and industrial development, especially from the Asia Pacific region. This has triggered multiple discussions among the stakeholders over balancing local supplies and international trade in fulfilling the growing demand, considering both the actual biomass potential and sustainability concerns in the potential producing countries. Meanwhile, the issue of switching from fossil fuel-based to renewable energy infrastructure was also perceived as a challenge in Japan and South Korea. Importantly, the lack of regulatory certainty in both countries has blocked the development of sustainable bioenergy systems in producing countries too. Due to its size (potential demand) and 
uncertainty in policy, China remains a wildcard that may drastically change the regional bioenergy landscape in the future. From a regional perspective, countries still need to work more closely through international platforms to address these challenges together.

Seeing the uncertainty in regional bioenergy supply chains, alternative decentralized bioenergy systems using local biomass resources have gained attention from researchers from different disciplines. Especially, such systems resonate among rural communities that have close interactions with forests with its potential advantages in forging synergies with rural revitalization and forest management. To explore the feasibility of such scenarios, Goh et al. (2019) identified five key questions. This covers not only the fundamental environmental, economic, and supply-demand aspects, but also a broader consideration of human-environmental relationships and framework to assess the overall sustainability from a rural development or revitalization perspective. Based on the knowledge collected through the literature and stakeholder discussions, the study concludes that such a scenario can only be realized with integrative management across sectors-forestry, energy, culture, local businesses, and community development. Importantly, local contexts must be carefully taken into account in designing such systems.

Kikuchi et al. (2020) further explore the above with an actual case study on a small, rather isolated island in Japan against the backdrop of resource security and population decline. Particularly, a co-learning approach was employed to assess the deployment of sustainable bioenergy systems based on available local resources, suitable technologies, and socio-economic conditions. The article reported large-scale co-learning efforts, processes, and results across 5 years, involving a large number of participants from various sectors, as well as residents in a series of events. These efforts not only allowed for the exchange of perspectives, but also evolved alongside the co-learning processes with tools like choice experiments and questionnaires. This study showed that such a co-learning framework could play a pivotal role in regional transformation with bioenergy as a central component.

Terada (2019) demonstrated the contribution of bioenergy to the land-use system's sustainability based on the 'satoyama' concept in Japan, i.e., sustainably managing a mosaic of forests, agricultural fields, grassland, streams, etc. on a landscape scale. Particularly, it focuses on the periurban areas in Japan, which is an important landscape in the country where large cities are still growing amidst of overall population decline. The study showed that harnessing benefits from small-scale utilization of biomass for heating and cooking, including during emergencies like earthquakes, can motivate landscape improvements by local communities. It provides a method to estimate the amount of biomass that can be generated through better management of trees dispersed across the landscape. While the various challenges in promoting such a concept were recognized, the study concluded that it could inspire more holistic thinking of urban-rural relations and sustainable lifestyles.

To better understand the socio-economic dynamics underlying the use of forest resources for different purposes, Oono et al. (2020) conducted a comprehensive literature review to analyze the causes and consequences of reduced utilization of formerly managed forests in Japan in comparison with other countries. It disclosed that the abandonment of former production forests in Japan has caused unwanted consequences like biodiversity decline and ecosystem disservices, although this was less reported for the other developed countries. The shift of Japan's policies from local wood production to imports is recognized as the root cause of forest abandonment in the country. The article emphasized that reactivating forest management is vital to replenish the ecosystem services provided by forests, and that material production and bioenergy can provide incentives for this. It also provokes the rethinking of forestry policies beyond the conventional private ownership, suggesting a more holistic approach for sustainable forest management.

Moving forward, the ongoing digital revolution may substantially affect and transform the existing land-use systems, providing new opportunities for bioenergy deployment. Especially, the current technical and logistical challenges may be gradually overcome with the application of smart technologies to optimize biomass supply chains in terms of efficiency and transparency. Ahl et al. (2019) contributed an article on how this can be effectively realized using the case of Japan as an example. The application does not limit to physical improvements like upgrades of transportation infrastructure and biomass quality management, but also business model integration and stakeholder relationship management. Based on field experience and in-depth communications with stakeholders, the study rightly pointed out that transparency and information sharing are among the critical elements to address socio-cultural barriers in bioenergy development, and smart technologies may provide solutions for these.

\section{Final remarks}

The various cases reported in this special feature demonstrated the roles of bioenergy in sustainable development, ranging from emission reduction to rural revitalization. Of particular interest are perspectives gathered from international to local scales, insights synthesized from upstream to downstream levels, and the usefulness of different methodologies across different cases. Even though international trade has been perceived as an important component of bioenergy 
development in Asia, the broader consideration of the role of bioenergy systems for rural revitalization and landscape management has also been frequently discussed. This provokes decision-makers to rethink the potential benefits and trade-offs of bioenergy development from a broader perspective. Importantly, it must be placed in a wider canvas of sustainable development that cuts across multiple SDGs beyond individual sectors, disciplines, institutions, and countries. Currently, bioenergy policies in Asia are still largely disconnected, placed under the premise of either energy system, environmental management (whether climate or forestry), or rural economic development. Synergies between these goals are seldom harnessed. Combining the different strategies depending on both local and regional conditions, as well as tapping on technological breakthroughs from the digital revolution, are critical to avoid unwanted consequences including both direct and indirect environmental degradation as well as local energy security. While studies in this special features disclosed these important aspects, more comprehensive research that integrates them is needed in the near future.

The studies presented in this special feature illustrate how sustainability science can be used to comprehensively address the complexity of bioenergy development, with Japan as the main focus country. While these case studies show that involving stakeholders in knowledge production is imperative, the development of long-term trust and relationships between stakeholders is still needed. This has to be carried out based on sound scientific foundations for sustainability. There have been various ongoing efforts in Japan, where researchers from institutes like National Institutes for Environmental Studies (NIES) and United Nations University (UNU) have been actively pushing for the incorporation of sustainability competencies in local bioenergy and forestry programs. In the future, researchers may need to be more proactive to kickstart collaboration among communities, governments, and industries in collectively addressing forestry, agriculture, energy, climate, and rural development based on sustainability science. How sustainability science evolves and transforms to address different problems will continue to be an essential topic for sustainability researchers.

Acknowledgements We thank all authors for their contributions to this Special Feature. We also express our gratitude to Ms. Shruti Lahoti for her great efforts in managing the schedule of this Special Feature especially in this challenging time.

\section{References}

Ahl A, Goto M, Yarime M (2019) Smart technology applications in the woody biomass supply chain: interview insights and potential in Japan. Sustain Sci. https://doi.org/10.1007/s11625-019-00728-2
Brewer JP, Vandever S, Johnson JT (2018) Towards energy sovereignty: biomass as sustainability in interior Alaska. Sustain Sci 13:417-429

Goh CS, Aikawa T, Ahl A et al (2019) Rethinking sustainable bioenergy development in Japan: decentralised system supported by local forestry biomass. Sustain Sci. https://doi.org/10.1007/ s11625-019-00734-4

Hayashi A, Sano F, Akimoto K (2020) On the feasibility of cropland and forest area expansions required to achieve long-term temperature targets. Sustain Sci 15:817-834

Johari A, Nyakuma BB, Nor SHM, Mat R, Hashim H, Ahmad A, Zakaria ZY, Abdullah TA (2015) The challenges and prospects of palm oil based biodiesel in Malaysia. Energy 81:255-261

Junginger HM, Mai-Moulin T, Daioglou V, Fritsche U, Guisson R, Hennig C, Thrän D, Heinimö J, Hess JR, Lamers P, Li C, Kwant K, Olsson O, Proskurina S, Ranta T, Schipfer F, Wild M (2019a) The future of biomass and bioenergy deployment and trade: a synthesis of 15 years IEA bioenergy task 40 on sustainable bioenergy trade. Biofuels Bioprod Biorefin 13:247-266

Junginger M, Koppejan J, Goh CS (2019b) Sustainable bioenergy deployment in East and South East Asia: notes on recent trends. Sustain Sci. https://doi.org/10.1007/s11625-019-00712-w

Kang S, Selosse S, Maïzi N (2015) Strategy of bioenergy development in the largest energy consumers of Asia (China, India, Japan and South Korea). Energy Strategy Rev 8:56-65

Karanja A, Mburu F, Gasparatos A (2020) A multi-stakeholder perception analysis about the adoption, impacts and priority areas in the Kenyan clean cooking sector. Sustain Sci 15:333-351

Kikuchi Y, Nakai M, Kanematsu Y et al (2020) Application of technology assessments to co-learning for regional transformation: a case study of biomass energy systems in Tanegashima. Sustain Sci. https://doi.org/10.1007/s11625-020-00801-1

Matsumoto KI, Hasegawa T, Morita K, Fujimori S (2019) Synergy potential between climate change mitigation and forest conservation policies in the Indonesian forest sector: implications for achieving multiple sustainable development objectives. Sustain Sci 14:1657-1672

METI (2017) Biomass power generation with ordinary wood. (In Japanese). http://www.meti.go.jp/committee/chotatsu_kakak u/pdf/032_01_00.pdf. Accessed 17 Apr 2018

Oono A, Kamiyama C, Saito O (2020) Causes and consequences of reduced human intervention to formerly managed forests in Japan and other countries. Sustain Sci. https://doi.org/10.1007/ s11625-020-00845-3

Rehman IH, Kar A, Arora A, Pal R, Singh L, Tiwari J, Singh VK (2012) Distribution of improved cook stoves: analysis of field experiments using strategic niche management theory. Sustain Sci 7:227-235

Renaud F, Zhou X, Bosher L, Barrett B, Huang S (2020) Synergies and trade-offs between sustainable development goals and targets: innovative approaches and new perspectives. Sustain Sci 15:1011-1011

Sansilvestri R, Cuccarollo M, Frascaria-Lacoste N, Benito-Garzon M, Fernandez-Manjarrés J (2020) Evaluating climate change adaptation pathways through capital assessment: five case studies of forest social-ecological systems in France. Sustain Sci 15:539-553

Scharlemann JPW, Brock RC, Balfour N et al (2020) Towards understanding interactions between sustainable development goals: the role of environment-human linkages. Sustain Sci. https://doi. org/10.1007/s11625-020-00799-6

Silveira S, Johnson FX (2016) Navigating the transition to sustainable bioenergy in Sweden and Brazil: lessons learned in a European and International context. Energy Res Soc Sci 13:180-193

Simangunsong BCH, Sitanggang VJ, Manurung EGT, Rahmadi A, Moore GA, Aye L, Tambunan AH (2017) Potential forest biomass 
resource as feedstock for bioenergy and its economic value in Indonesia. For Policy Econ 81:10-17

Terada T (2019) Evaluating landscape improvement scenarios from the perspective of biomass production: a case study of peri-urban satoyama woodland in the Tokyo Metropolitan Area. Sustain Sci. https://doi.org/10.1007/s11625-019-00724-6

Wiek A, Harlow J, Melnick R, van der Leeuw S, Fukushi K, Takeuchi K, Farioli F, Yamba F, Blake A, Geiger C, Kutter R (2015) Sustainability science in action: a review of the state of the field through case studies on disaster recovery, bioenergy, and precautionary purchasing. Sustain Sci 10:17-31
Yamagata Y, Hanasaki N, Ito A, Kinoshita T, Murakami D, Zhou Q (2018) Estimating water-food-ecosystem trade-offs for the global negative emission scenario (IPCC-RCP2.6). Sustain Sci 13:301-313

Publisher's Note Springer Nature remains neutral with regard to jurisdictional claims in published maps and institutional affiliations. 